\title{
KOMITMEN DAN BUDAYA ORGANISASI TERHADAP KINERJA KARYAWAN BANK bjb CABANG TAMANSARI
}

\author{
Adelia Farhani Romadhona \\ adeliafarhani@gmail.com \\ Ratri Wahyuningtyas \\ Universitas Telkom
}

diterima: 26/12/2018; direvisi:8/2/2019; diterbitkan: 27/2/2019

\begin{abstract}
This research aims to determine the organizational commitment, organizational culture, and employee performance at Bank BJB Branch Office Tamansari Bandung, and the effect of organizational commitment and organizational culture to the employee performance, both partially and simultaneously. This research uses quantitative method. Data collection technique uses questionnaires distributed to employees of Bank BJB Branch Office Tamansari Bandung, with the population of 160 employees and the samples 115 employees. The sampling technique uses simple random sampling. To interpret the results of the research uses descriptive analysis, correlation analysis, path analysis, and coefficient of determination. The result of data proccessing shows that organizational commitment and organizational culture significantly influence the employee performance at Bank BJB Branch Office Tamansari Bandung, both partially and simultanously.
\end{abstract}

Keywords: organizational commitment; organizational culture; employee performance

\begin{abstract}
Abstrak
Penelitian ini bertujuan untuk mengetahui komitmen organisasi, budaya organisasi, dan kinerja karyawan di PT. Bank bjb Kantor Cabang Tamansari Bandung, serta pengaruh komitmen organisasi dan budaya organisasi terhadap kinerja karyawan pada PT. Bank bjb Kantor Cabang Tamansari Bandung baik secara parsial, maupun simultan. Penelitian ini menggunakan metode kuantitatif. Teknik pengumpulan data menggunakan kuesioner yang disebarkan kepada karyawan PT. Bank bjb Kantor Cabang Tamansari Bandung, dengan populasi sebanyak 160 karyawan dan sampel diambil sebanyak 115 karyawan. Teknik sampling menggunakan simple random sampling. Untuk menginterpretasikan hasil penelitian menggunakan analisis deskriptif, analisis korelasi berganda, analisis jalur, dan koefisien determinasi. Hasil pengolahan data menunjukkan komitmen organisasi dan budaya organisasi berpengaruh secara signifikan terhadap kinerja karyawan pada Bank bjb Kantor Cabang Tamansari Bandung, baik secara parsial maupun simultan.
\end{abstract}

Kata Kunci: komitmen organisasi; budaya organisasi; kinerja karyawan 


\section{PENDAHULUAN}

Bisnis perbankan merupakan bisnis yang memiliki tingkat persaingan yang tinggi, dimana bank tidak hanya berkompetisi dengan sesama bisnis perbankan saja, tetapi juga dengan institusi keuangan selain bank. Agar organisasi dapat bersaing dengan organisasi lainnya, dibutuhkan pengelolaan sumber daya yang baik sehingga sasaran dan tujuan organisasi tercapai. Sumber daya manusia merupakan keunggulan kompetitif. Sumber daya manusia paling efektif dikembangkan dan didorong oleh kebijakan yang konsisten, yang mendorong munculnya komitmen pegawai untuk menyesuaikan diri terhadap tuntutan perubahan dan kepentingan organisasi dalam rangka menciptakan keunggulan (Armstrong; dalam Priansa, 2014:20).

Hal yang dapat menjadi tolak ukur keberhasilan perusahaan diantaranya adalah kinerja karyawan. Kinerja merupakan sebuah penggambaran mengenai tingkat pencapaian pelaksanaan suatu program kegiatan atau kebijakan (Moeheriono, 2012:95). Selanjutnya, kinerja karyawan berperan penting bagi organisasi. Rendahnya kinerja pegawai akan menghambat suatu organisasi dalam mencapai tujuannya. (Sedarmayanti, 2017:21). Metode yang dilakukan untuk menilai kinerja dari setiap karyawan telah memiliki standar penilaian masing-masing tergantung perusahaannya.

Pada PT. Bank Pembangunan Daerah Jawa Barat dan Banten, Tbk. (Bank bjb), standar penilaian kinerja disebut Penilaian Prestasi Kerja Individu atau disebut Key Performance Individu (KPI). Kinerja karyawan Bank bjb diukur dengan penilaian evaluasi kinerja, tujuannya yaitu untuk melihat dan menentukan karyawan mana yang telah bekerja sesuai dengan standar kerja yang telah ditetapkan oleh perusahaan. Penilaian tersebut dilakukan setiap tiga bulan (triwulan) dalam 1 (satu) tahun.

Tabel 1. Penilaian Kinerja Karyawan Bank bjb Kantor Cabang Tamansari Bandung Periode 2017 - 2018

\begin{tabular}{ccccccc}
\hline & \multicolumn{6}{c}{ Tahun } \\
\cline { 2 - 7 } Kategori & \multicolumn{5}{c}{2017} \\
\cline { 2 - 7 } Kinerja & \multicolumn{5}{c}{ Triwulan (Jumlah Karyawan) } \\
\cline { 2 - 7 } & I & II & III & IV & I & II \\
\hline PL 1 & 15 & 18 & 17 & 20 & 19 & 17 \\
PL 2 & 58 & 55 & 60 & 62 & 65 & 68 \\
PL 3 & 83 & 86 & 78 & 74 & 73 & 72 \\
PL 4 & 1 & 1 & 3 & 2 & 2 & 3 \\
\hline Total & 157 & 160 & 158 & 158 & 159 & 160 \\
\hline Sunyyyyyy
\end{tabular}

Sumber: Data Internal Bank bjb Kantor Cabang Tamansari Bandung

Hasil rekapitulasi rata-rata penilaian kinerja karyawan pada Bank bjb Kantor Cabang Tamansari Bandung selama periode 2017-2018 (Tabel 1) belum optimal, dimana untuk kategori PL 4 (need improvement) cenderung meningkat, sedangkan target perusahaan untuk kategori PL 4 yaitu mencapai angka 0. Sementara itu untuk kategori PL 1 (excellent) masih dalam kondisi tidak stabil. Oleh karena itu perlu pengelolaan sumber daya manusia dengan baik agar kinerja karyawan meningkat.

Menurut Kasmir (2016:34) terdapat faktor yang menyebabkan sumber daya manusia memiliki kinerja yang baik, sehingga dapat mendorong keberhasilan organisasi. Salah satu faktor yang dapat mempengaruhi kinerja karyawan adalah komitmen. Penelitian Fatmawati \& Gustina Pane (2017), Adiftiya (2014), Hafiz (2017), dan Irefin \& Mechanic (2014), menunjukkan bahwa komitmen organisasi berpengaruh signifikan terhadap kinerja karyawan.

Sopiah dalam Priansa (2014:236) mengemukakan bahwa karyawan yang berkomitmen rendah akan berdampak pada turnover, tingginya absensi, meningkatnya kelambanan kerja, dan kurangnya intensitas untuk bertahan, rendahnya kualitas kerja, dan kurangnya loyalitas pada organisasi. Data yang diperoleh dari Bank bjb Kantor Cabang Tamansari Bandung menunjukkan bahwa turnover karyawan Bank bjb Kantor Cabang Tamansari Bandung dari tahun 2015 sampai dengan tahun 2017 mengalami peningkatan (Tabel 2). Selain itu, tingkat ketidakhadiran karyawan Bank bjb Kantor Cabang Tamansari Bandung selama periode Maret 2018 hingga Agustus 2018 cenderung mengalami peningkatan (Gambar 1), sedangkan target perusahaan yaitu mencapai angka $0 \%$.

Tabel 2. Turnover Karyawan Bank bjb Kantor Cabang Tamansari Bandung Periode 2015-2017

\begin{tabular}{cccc}
\hline Tahun & $\begin{array}{c}\text { Jumlah Karyawan } \\
\text { Resign }\end{array}$ & $\begin{array}{c}\text { Jumlah } \\
\text { Karyawan }\end{array}$ & $\begin{array}{c}\text { Turnover } \\
\text { Karyawan (\%) }\end{array}$ \\
\hline 2015 & 5 & 156 & 3.21 \\
2016 & 6 & 158 & 3.80 \\
2017 & 8 & 157 & 5.10 \\
\hline Sumber: Data Internal Bank bjb Kantor Cabang Tamansari Bandung
\end{tabular}

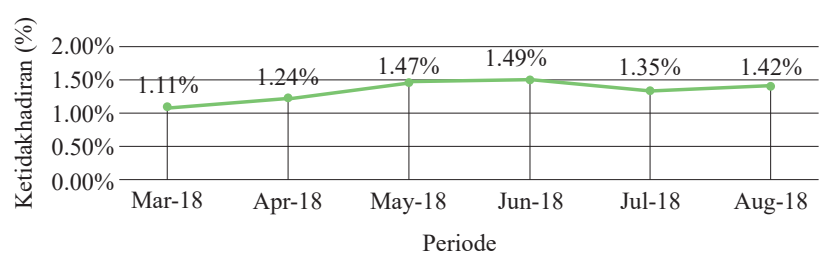

Sumber: Diolah dari Data Internal Bank bjb Kantor Cabang Tamansari

Gambar 1. Tingkat Ketidakhadiran Karyawan Bank bjb Kantor Cabang Tamansari Bandung Periode Maret 2018-Agustus 2018

Selain komitmen organisasi, faktor lain yang menentukan kinerja karyawan yaitu budaya organisasi. Penelitian Putri (2016), Baan (2015), Mohamed \& Abukar (2016), Emeka \& Philemon (2012), menunjukkan bahwa budaya organisasi berpengaruh signifikan terhadap kinerja karyawan. 


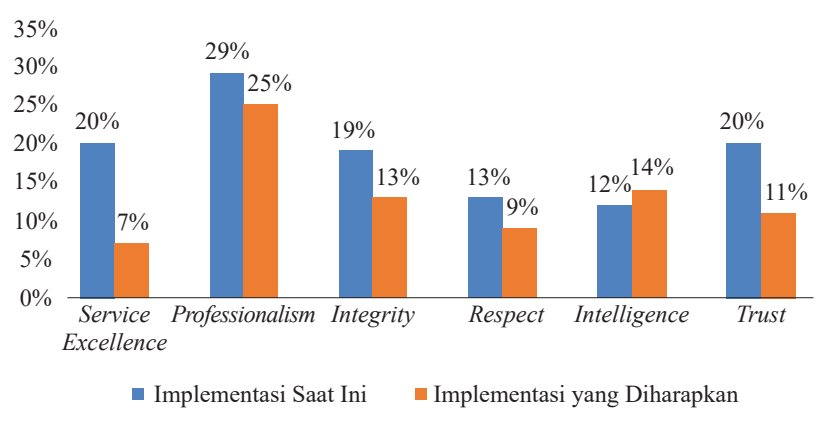

Sumber: Data Internal Bank bjb Kantor Cabang Tamansari Bandung

Gambar 2. Implementasi Budaya Organisasi Bank bjb Kantor Cabang Tamansari Bandung Tahun 2017

Bank bjb memiliki pengukuran budaya organisasi yang disebut "GO SPIRIT" dengan 6 (enam) nilai di dalamnya, yaitu Service Excellence, Professionalism, Integrity, Respect, Intelligence, dan Trust. Berdasarkan data yang diperoleh penulis pada Gambar 2, terdapat 1 (satu) nilai budaya organisasi pada Bank bjb Kantor Cabang Tamansari Bandung yang belum mencapai target yang diharapkan, yaitu Intelligence. Tingkat implementasi yang diharapkan yaitu sebesar 14\%, sedangkan implementasi yang dicapai yaitu sebesar $12 \%$ artinya masih terdapat gap sebesar $2 \%$ dari target yang diharapkan perusahaan.

Komitmen organisasi mencerminkan bagaimana seorang individu mengidentifikasikan dirinya dengan organisasi dan terikat dengan tujuan-tujuannya (Kaswan, 2017:353). Komitmen organisasi adalah keadaan di mana seorang karyawan memihak pada organisasi beserta tujuannya dan berniat memelihara keanggotaannya (Triana, 2015:120) dan Priansa (2014:234). Menurut Allen dan Meyer dalam Darmawan (2013:169) ada 3 (tiga) dimensi komitmen organisasi, yaitu:(1) Komitmen Afektif (affective commitment); (2) Komitmen berkelanjutan (continuance commitment); (3) Komitmen normatif (normative commitment).

Menurut Sinambela (2016:335) budaya organisasi merupakan sebuah sistem makna bersama yang membedakan suatu organisasi dengan organisasi lainnya. Sedangkan menurut Ernawan (2016:136), budaya organisasi tumbuh karena diciptakan dan dikembangkan dalam organisasi, dan diterima sebagai nilai-nilai yang harus dipertahankan. Menurut Sembiring (2012:39), budaya organisasi merupakan karakteristik organisasi. Denison, et.al. (2012:7) mengemukakan ada 4 (empat) dimensi budaya organisasi yaitu: (1) Misi (mission), sejauh mana organisasi dan anggotanya mengetahui arah tujuannya, bagaimana mereka akan kesana, dan bagaimana setiap individu dapat berkontribusi untuk keberhasilan organisasi; (2) Adaptabilitas (adaptability), suatu organisasi yang dapat beradaptasi, memiliki kemampuan untuk menerjemahkan permintaan pasar terhadap aksi; (3) Keterlibatan (involvement), tingkat dimana individu atau karyawan di semua fungsi organisasi didorong oleh perusahaan dalam berkontribusi pada pekerjaan mereka dan membangun serta tanggung jawab untuk terlibat dalam mencapai misi dan bekerjasama untuk memenuhi tujuan organisasi; (4) Konsistensi (consistensy), tingkat konsistensi organisasi dalam mengembangkan pola pikir mengenai lakukan dan tidak lakukan.

Menurut Priansa (2014:278) kinerja merupakan tingkat keberhasilan pegawai dalam menyelasaikan pekerjaannya. Sinambela (2016:5) mengemukakan bahwa kinerja karyawan adalah kemampuan pegawai dalam melakukan sesuatu keahlian tertentu. Sedangkan kinerja menurut Moeheriono (2012:95) merupakan sebuah penggambaran mengenai tingkat pencapaian pelaksanaan suatu program kegiatan atau kebijakan dalam mewujudkan sasaran, tujuan, visi, dan misi organisasi yang dituangkan dalam suatu perencanaan strategis organisasi.

Mondy et al.; dalam Priansa (2014:271) menyatakan bahwa pengukuran kinerja dapat dilakukan dengan menggunakan beberapa dimensi, antara lain: (1) Kuantitas Pekerjaan (quantity of work), berhubungan dengan volume pekerjaan dan produktivitas kerja yang dihasilkan oleh pegawai dalam kurun waktu tertentu; (2) Kualitas pekerjaan (quality of work), berhubungan dengan pertimbangan ketelitian, presisi, kerapian dan kelengkapan di dalam menangani tugas-tugas yang ada di dalam organisasi; (3) Kemandirian (dependability), berkenaan dengan pertimbangan derajat kemampuan pegawai untuk bekerja dan mengembangkan tugas secara mandiri dengan meminimalisir bantuan orang lain; (4) Inisiatif (initiative), berkenaan dengan pertimbangan kemandirian, fleksibilitas berfikir, dan kesediaan untuk menerima tanggungjawab; (5) Adaptabilitas (adaptability), berkenaan dengan kemampuan seseorang untuk beradaptasi, mempertimbangkan kemampuan untuk bereaksi terhadap mengubah kebutuhan dan kondisi-kondisi; (6) Kerjasama (cooperation), berkaitan dengan pertimbangan kemampuan untuk bekerjasama, dan dengan orang lain.

Robbins (2011:556) mengemukakan bahwa budaya yang kuat adalah budaya dimana nilai-nilai inti dipegang secara intensif dan dianut bersama secara meluas. Semakin banyak anggota yang menerima nilai-nilai inti, semakin besar komitmen mereka pada nilai-nilai itu, maka makin kuat pula budaya tersebut.

Penelitian yang dilakukan oleh (Momeni, Marjani, Saadat, \& Branch, 2012) menyatakan bahwa terdapat hubungan antara budaya organisasi dan komitmen organisasi. Penelitian lainnya dilakukan oleh (Herman, 2016) mengemukakan bahwa budaya organisasi memiliki hubungan positif dengan komitmen organisasi.

Kaswan (2017:354) mengemukakan bahwa dalam organisasi, komitmen tinggi karyawan sangat besar dampaknya terhadap keberlangsungan, kemajuan, dan kesuksesan organisasi. Dengan adanya komitmen yang tinggi pada setiap karyawan dapat menghindari 
kemungkinan adanya kinerja karyawan yang menurun, selain itu juga karyawan dapat bertanggung jawab dengan pekerjaannya masing-masing. Selain itu, menurut Wibowo (2016:435) bahwa penting untuk dilakukan observasi terhadap tingkat antusiasme dan komitmen yang ditunjukan pekerja terhadap kesepakatan sasaran dan tingkat kinerja.

Penelitian yang dilakukan oleh Rivai dan Pramusinto (2005), Wahyuni et al. (2014), Irefin dan Mechanic (2014) dalam (Tanuwibowo \& Sutanto, 2014) menyatakan bahwa komitmen organisasi mempengaruhi kinerja, komitmen organisasi juga dapat meningkatkan kinerja karyawan.

Nawawi (2013:226) mengemukakan bahwa karyawan yang sudah memahami seluruh nilai-nilai organisasi akan menjadikan nilai-nilai tersebut sebagai suatu kepribadian organisasi. Mangkunegara (2010:29) menyatakan bahwa kinerja yang baik dihasilkan jika terdapat komunikasi antara seluruh karyawan sehingga membentuk internalisasi budaya organisasi yang kuat dan dipahami sesuai dengan nilai-nilai organisasi yang dapat menimbulkan persepsi yang positif antara semua tingkatan karyawan untuk mendukung dan mempengaruhi iklim kepuasan yang berdampak pada kinerja.

Penelitian yang dilakukan oleh Soedjono (2005), Porwani (2010), Brahmasari dan Suprayitno (2008), Mulyadi et al. (2012) dalam (Tanuwibowo \& Sutanto, 2014) menyatakan budaya organisasi memiliki pengaruh positif dan signifikan terhadap kinerja karyawan, sehingga semakin kuat budaya organisasi, maka semakin tinggi kinerja karyawan.

Hipotesis dalam penelitian ini sebagai berikut: (1) Terdapat pengaruh komitmen organisasi terhadap kinerja karyawan; (2) Terdapat pengaruh budaya organisasi terhadap kinerja karyawan; (3) Terdapat pengaruh komitmen organisasi dan budaya organisasi terhadap kinerja karyawan.

\section{METODE}

Metode yang digunakan adalah metode kuantitatif dengan penelitian deskriptif dan kausal. Populasi dalam penelitian ini yaitu karyawan Bank bjb Kantor Cabang Tamansari Bandung berjumlah 160 orang, sampel dengan teknik probability sampling dengan tipe simple random sampling. Hasil perhitungannya diperoleh sampel berjumlah 115 responden. Metode analisis data yang digunakan adalah analisis jalur.

\section{HASIL}

Variabel komitmen organisasi diwakili oleh 13 item pernyataan, variabel budaya organisasi diwakili oleh 21 pernyataan, dan variabel kinerja karyawan diwakili oleh 16 pernyataan. Hasil analisis deskriptif masing-masing variabel, ditunjukkan pada Gambar 3, Gambar 4, dan Gambar 5.

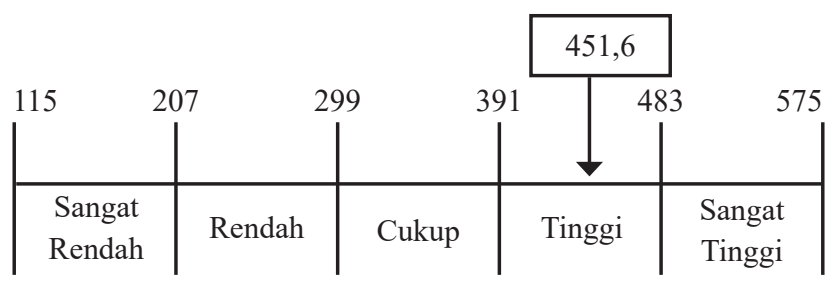

Gambar 3. Garis Kontinum Komitmen Organisasi

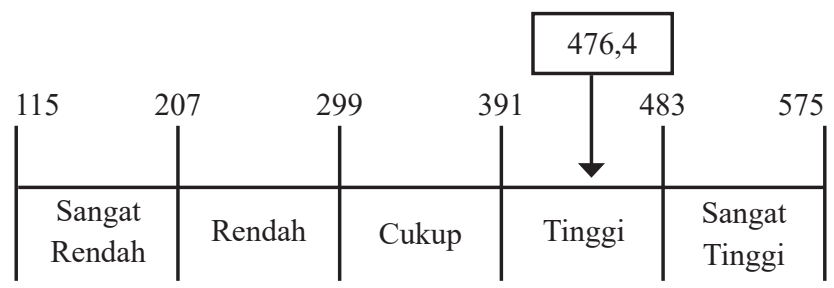

Gambar 4. Garis Kontinum Budaya Organisasi

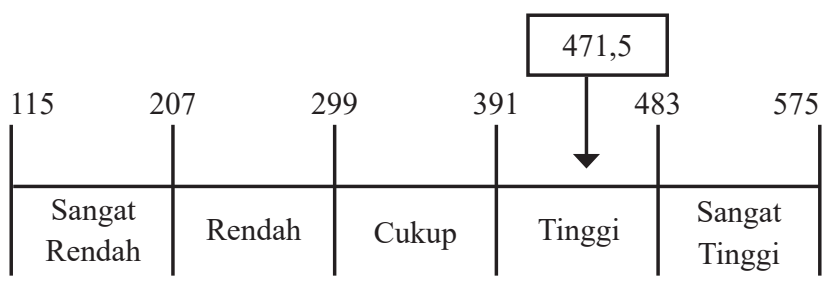

Gambar 5. Garis Kontinum Kinerja Karyawan

Koefisien korelasi antara komitmen organisasi dengan budaya organisasi sebesar 0,340 termasuk dalam kategori rendah dengan nilai signifikansi nol (Tabel 3).

Pengujian secara simultan (Tabel 4) menunjukkan komitmen organisasi dan budaya organisasi berpengaruh signifikan terhadap kinerja karyawan secara simultan pada Bank bjb Kantor Cabang Tamansari Bandung.

Tabel 3. Korelasi Antara Variabel Independen

\begin{tabular}{clcc}
\hline \multicolumn{3}{c}{ Correlations } \\
\hline \multicolumn{1}{c}{ X1 } & Pearson Correlation & $\mathrm{X}_{1}$ & $\mathrm{X}_{2}$ \\
& Sig. (2-tailed) & & $.340^{* *}$ \\
& $\mathrm{~N}$ & 115 & .000 \\
$\mathrm{X} 2$ & Pearson Correlation & $.340^{* *}$ & 115 \\
& Sig. (2-tailed) & .000 & 1 \\
& $\mathrm{~N}$ & 115 & 115 \\
\hline
\end{tabular}

Tabel 4. Hasil Uji F (Simultan)

ANOVA $^{\mathrm{a}}$

\begin{tabular}{lrrrrrr}
\hline \multicolumn{2}{l}{ Model } & $\begin{array}{c}\text { Sum of } \\
\text { Squares }\end{array}$ & Df & $\begin{array}{r}\text { Mean } \\
\text { Square }\end{array}$ & F & Sig. \\
\hline 1 & Regression & 18.186 & 2 & 9.093 & 66.594 & $.000^{\mathrm{b}}$ \\
& Residual & 15.292 & 112 & .137 & & \\
& Total & 33.478 & 114 & & & \\
\hline
\end{tabular}

a. Dependent Variable: Y

b. Predictors: (Constant), X2, X1 


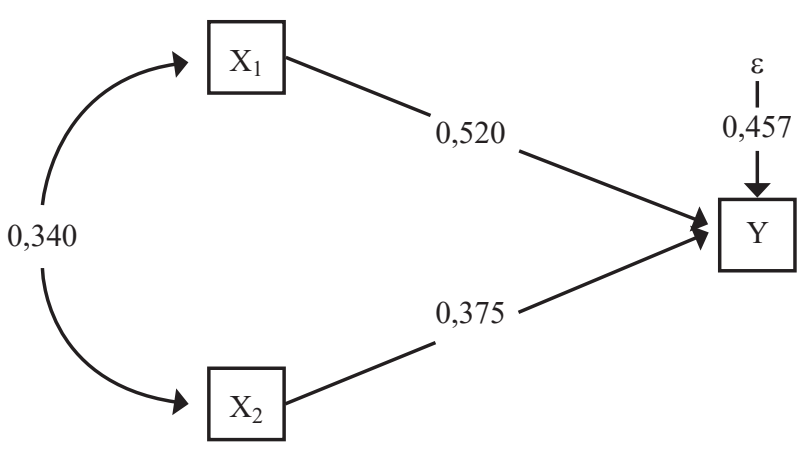

Gambar 6. Diagram Jalur Hasil Penelitian

Secara visual diagram jalur pengaruh komitmen organisasi dan budaya organisasi terhadap kinerja karyawan ditunjukkan pada Gambar 6. Persamaan jalur pada penelitian ini sebagai berikut:

$$
\mathrm{Y}=0,520 \mathrm{X}_{1}+0,375 \mathrm{X}_{2}+0,457 \varepsilon
$$

Melalui koefisien determinasi (nilai $\mathrm{R}^{2}$ ) pada Tabel 5 dapat diketahui kedua variabel independen (komitmen organisasi dan budaya organisasi) memberikan kontribusi (pengaruh) sebesar 54,3\% terhadap kinerja karyawan pada Bank bjb Kantor Cabang Tamansari Bandung.

Tabel 5. Hasil Koefisien Determinasi Model Summary ${ }^{\mathrm{b}}$

\begin{tabular}{lrrrr}
\hline Model & R & R Square & $\begin{array}{c}\text { Adjusted R } \\
\text { Square }\end{array}$ & $\begin{array}{l}\text { Std. Error of } \\
\text { the Estimate }\end{array}$ \\
\hline 1 & $.737^{\mathrm{a}}$ & .543 & .535 & .36951 \\
\hline
\end{tabular}

a. Predictors: (Constant), X2, X1

b. Dependent Variable: $\mathrm{Y}$

\section{PEMBAHASAN}

Komitmen organisasi pada Bank bjb Kantor Cabang Tamansari Bandung masuk dalam kategori tinggi. Hal ini didukung oleh dimensi penelitian yaitu komitmen afektif, komitmen berkelanjutan, dan komitmen normatif.Namun penulis menemukan kelemahan dalam implementasi komitmen organisasi perusahaan, yaitu masih ada beberapa karyawan yang tidak berkeinginan menghabiskan sepanjang karirnya di perusahaan.

Budaya organisasi pada Bank bjb Kantor Cabang Tamansari Bandung masuk dalam kategori tinggi. Hal ini didukung oleh dimensi penelitian yaitu misi, adaptabilitas, keterlibatan, dan konsistensi. Namun penulis masih menemukan kelemahan dalam implementasi budaya organisasi di perusahaan yaitu masih terdapat beberapa karyawan yang tidak memiliki kesepakatan tentang hal-hal yang salah dalam melaksanakan pekerjaannya dan belum mengetahui tujuan jangka panjang perusahaan.

Kinerja karyawan pada Bank bjb Kantor Cabang Tamansari Bandung masuk dalam kategori baik. Hal ini didukung oleh dimensi penelitian yaitu kuantitas pekerjaan, kualitas pekerjaan, kemandirian, inisiatif, adaptabilitas, dan kerjasama. Namun penulis masih menemukan kelemahan dalam kinerja perusahaan yaitu masih ada beberapa karyawan yang tidak berkeinginan mengerjakan pekerjaannya, walaupun mereka mampu, sebelum adanya instruksi dari atasan, biasanya mereka ini adalah karyawan junior yang belum diberikan kewenangan lebih serta masih sedikit pengalamannya.

Tabel 6. Hasil Uji t (Parsial) Coefficients $^{\mathrm{a}}$

\begin{tabular}{|c|c|c|c|c|c|c|}
\hline & \multirow[t]{2}{*}{ Model } & \multicolumn{2}{|c|}{$\begin{array}{l}\text { Unstandardized } \\
\text { Coefficients }\end{array}$} & \multirow{2}{*}{$\begin{array}{c}\begin{array}{c}\text { Standardized } \\
\text { Coefficients }\end{array} \\
\text { Beta }\end{array}$} & \multirow[t]{2}{*}{$\mathrm{t}$} & \multirow[t]{2}{*}{ Sig. } \\
\hline & & B & Std. Error & & & \\
\hline \multirow[t]{3}{*}{1} & (Constant) & -.010 & .264 & & -.037 & .971 \\
\hline & $\mathrm{X} 1$ & .551 & .072 & .520 & 7.651 & .000 \\
\hline & $\mathrm{X} 2$ & .433 & .078 & .375 & 5.523 & .000 \\
\hline
\end{tabular}

Hasil penelitian menunjukkan bahwa komitmen organisasi berpengaruh positif dan signifikan terhadap kinerja karyawan pada Bank bjb Kantor Cabang Tamansari Bandung (Tabel 6). Secara total, komitmen organisasi memberikan pengaruh sebesar $33,6 \%$ terhadap kinerja karyawan. Hasil pengujian ini memberikan bukti empiris bahwa semakin tinggi komitmen organisasi akan membuat kinerja karyawan semakin baik. Dengan adanya komitmen yang tinggi, karyawan akan merasa senang dan bangga bekerja di perusahaan, sehingga memunculkan rasa bertanggung jawab dan bersungguh-sungguh dalam bekerja demi tercapainya tujuan organisasi. Dengan begitu, kinerja karyawan akan meningkat. Penelitian ini konsisten dengan teori yang diungkapkan oleh Kaswan (2017:354) bahwa dalam organisasi, komitmen tinggi karyawan sangat besar dampaknya terhadap keberlangsungan, kemajuan, dan kesuksesan organisasi. Dengan adanya komitmen yang tinggi pada setiap karyawan dapat menghindari kemungkinan adanya kinerja karyawan yang menurun, selain itu juga karyawan dapat bertanggung jawab dengan pekerjaannya masingmasing. Selain itu, menurut Wibowo (2016:435) bahwa penting untuk dilakukan observasi terhadap tingkat antusiasme dan komitmen yang ditunjukan pekerja terhadap kesepakatan sasaran dan tingkat kinerja. Selain itu, penelitian ini juga konsisten dengan penelitian Rivai dan Pramusinto (2005), Wahyuni et al. (2014), Irefin dan Mechanic (2014), Pane dan Fatmawati (2017), Adiftiya (2014), Hafiz (2017), Irefin dan Mechanic (2014) yang menunjukkan bahwa komitmen organisasi berpengaruh terhadap kinerja karyawan.

Hasil penelitian juga menunjukkan bahwa budaya organisasi berpengaruh positif dan signifikan terhadap kinerja karyawan pada Bank bjb Kantor Cabang Tamansari Bandung. Secara total, budaya organisasi 
memberikan pengaruh sebesar 20,7\% terhadap kinerja karyawan. Hasil pengujian ini memberikan bukti empiris bahwa semakin tinggi budaya organisasi akan membuat kinerja karyawan pada Bank bjb Kantor Cabang Tamansari Bandung semakin baik. Pada praktiknya, penilaian kinerja karyawan pada Bank bjb Kantor Cabang Tamansari Bandung juga melihat dari sisi pemahaman serta implementasi karyawan atas budaya organisasi. Sehingga, demi tercapainya kinerja karyawan yang baik, perusahaan mendorong karyawannya untuk menjunjung tinggi nilai-nilai perusahaan, etika bisnis, dan kebijakan perusahaan. Penelitian ini konsisten dengan teori yang diungkapkan oleh Nawawi (2013:226) bahwa karyawan yang sudah memahami seluruh nilai-nilai organisasi akan menjadikan nilainilai tersebut sebagai suatu kepribadian organisasi. Selain itu penelitian ini konsisten dengan teori yang diungkapkan oleh Mangkunegara (2010:29). Penelitian ini juga konsisten dengan penelitian yang dilakukan oleh Soedjono (2005), Porwani (2010), Brahmasari dan Suprayitno (2008), Mulyadi et al. (2012), Putri (2016), Baan (2015), Mohamed dan Abukar (2013), Philemon (2012) yang menunjukkan bahwa budaya organisasi memiliki pengaruh positif dan signifikan terhadap kinerja karyawan.

Secara simultan, komitmen organisasi dan budaya organisasi berpengaruh terhadap kinerja karyawan pada Bank bjb Kantor Cabang Tamansari Bandung sebesar $54,3 \%$. Perpaduan komitmen organisasi dan budaya organisasi yang tinggi diharapkan dapat meningkatkan kinerja karyawan. Penelitian ini konsisten dengan teori Kasmir (2016:34), yang menyatakan bahwa komitmen organisasi dan budaya organisasi merupakan faktor yang menyebabkan sumber daya manusia memiliki kinerja yang baik, sehingga dapat mendorong keberhasilan organisasi.

\section{KESIMPULAN}

Berdasarkan hasil penelitian dan pembahasan dapat ditarik kesimpulan sebagai berikut: (1) Karyawan di Bank bjb Kantor Cabang Tamansari Bandung memiliki komitmen yang tinggi. Implementasi budaya organisasi sudah baik. Karyawan sudah memiliki kinerja yang baik; (2) Total pengaruh komitmen organisasi terhadap kinerja karyawan pada Bank bjb Kantor Cabang Tamansari Bandung yaitu 33,6\%. Total pengaruh budaya organisasi terhadap kinerja karyawan sebesar 20,7\%. Secara simultan, komitmen organisasi dan budaya organisasi berpengaruh terhadap kinerja karyawan sebesar $54,3 \%$.

\section{DAFTAR PUSTAKA}

Adiftiya, J., 2014. Pengaruh Komitmen Organisasi terhadap Kinerja Karyawan pada PT. Bukit Makmur Mandiri Utama Site Kideco Jaya Agung Batu
Kajang Kabupaten Paser. eJournal Ilmu Adm. Bisnis 2, 833-845.

Baan, Y.F., 2015. Pengaruh Budaya Organisasi Terhadap Kinerja Karyawan Pada Hotel Grand Victoria Di Samarinda. e-Journal Ilmu Adm. Bisnis ISSN 23555408 3, 675-686.

Brahmasari, I.A. and Suprayetno, A., 2009. Pengaruh motivasi kerja, kepemimpinan dan budaya organisasi terhadap kepuasan kerja karyawan serta dampaknya pada kinerja perusahaan (Studi kasus pada PT. Pei Hai International Wiratama Indonesia). Jurnal Manajemen dan kewirausahaan, 10(2), pp.124-135. Darmawan, D., 2013. Metode penelitian kuantitatif.

Denison, D., Hooijberg, R., Lane, N. and Lief, C., 2012. Leading culture change in global organizations: Aligning culture and strategy (Vol. 394). John Wiley \& Sons.

Emeka, N., \& Philemon, A., 2012. The Impact of Organizational Culture on Employee Performance a Study of Selected Manufacturing Industry in Enugu. Asian J. Bus. Manag. Stud. 3, 13-19.

Ernawan, F., 2016. Robust image watermarking based on psychovisual threshold. Journal of ICT Research and Applications, 10(3), pp.228-242.

Fatmawati, Gustina Pane, S., 2017. Pengaruh Komitmen Organisasi Terhadap Kinerja Pegawai. Pengaruh Komitmen Organ. Terhadap Kinerja Pegawaig 2, $1-13$.

Hafiz, A., 2017. Relationship between Organizational Commitment and Employee's Performance Evidence from Banking Sector of Lahore. Arab. J. Bus. Manag. Rev. 7, 7.

Herman, 2016. Hubungan antara Budaya Organisasi dan Kepuasan Kerja Dengan Komitmen Terhadap Organisasi. J. Ilm. Manaj. Fak. Ekon. 2, 18-32.

Irefin, P., Mechanic, M.A., 2014. Effect of Employee Commitment on Organizational Performance in Coca Cola Nigeria Limited Maiduguri, Borno State. IOSR J. Humanit. Soc. Sci. 19, 33-41.

Kasmir. 2016. Manajemen Sumber Daya Manusia (Teori dan Praktik). Depok : PT. Rajagrafindo Persada.

Kaswan. 2017. Psikologi Industri dan Organisasi. Cetakan 1, Bandung: Alfabeta.

Mangkunegara, A.A.P., 2010. Evaluasi Kerja SDM, Bandung: PT. Refika Aditama.

Moeheriono, E. and Si, D.M., 2012. Pengukuran Kinerja Berbasis Kompetensi.

Mohamed, A.I., Abukar, A.A.S., 2016. The impact of Organizational Culture on Employees Performance of Mogadishu Universities. SAVAP Int. 3, 1-15.

Momeni, M., Marjani, A.B., Saadat, V., Branch, C.T., 2012. The Relationship between Organizational Culture and Organizational Commitment in Staff Department of General Prosecutors of Tehran. Int. J. Bus. Soc. Sci. 3, 217-222.

Nawawi, Ismail. 2013. Budaya organisasi kepemimpinan dan Kinerja. Jakarta: PT. Fajar Iterpratama Mandiri. 
Porwani, S., 2010. Pengaruh Budaya Organisasi terhadap Kinerja Karyawan Studi Kasus: PT. Tambang Batubara Bukit Asam (Persero) Tanjung Enim.

Putri, I.S., 2016. Pengaruh Budaya Organisasi Terhadap Kinerja Pegawai Di Dinas Pendidikan dan Kebudayaan Kota Samarinda 4, 4802-4816.

Priansa, D.J., 2014. Kesekretarisan. Bandung: Alfabeta.

Rivai, H. A. dan Pramusinto. 2005. Pengaruh Motivasi, Komitmen Organisasional dan Kompetensi Terhadap Kinerja individual. Kajian Bisnis STIE Widya Wiwaha Yogyakarta, 13(3): 272-286.

Robbins, S.P. and Judge, T.A., 2006. Perilaku organisasi. Edisi kesepuluh. Jakarta: PT Indeks Kelompok Gramedia.

Sedarmayanti. 2017. Manajemen Sumber Daya Manusia. Bandung: Refika Aditama.

Sembiring, M., 2012. Budaya dan kinerja organisasi: perspektif organisasi pemerintah. Fokusmedia.

Sinambela, L.P., 2016. Manajemen Sumber Daya Manusia. Bumi Aksara. Jakarta.
Soedjono, S., 2005. Pengaruh budaya organisasi Terhadap kinerja organisasi dan kepuasan kerja karyawan pada terminal penumpang umum di surabaya. Jurnal Manajemen dan Kewirausahaan, 7(1), pp.22-47.

Tanuwibowo, J.C., \& Sutanto, E.M., 2014. Hubungan Budaya Organisasi dan Komitmen Organisasional pada Kinerja Karyawan. J. Trikonomika, ISSN 2355-7737 13, 136-144.

Triana, Cepi. 2015. Perilaku Organisasi Dalam Pendidikan. Bandung : PT Remaja Rosdakarya.

Wahyuni, D.U., Christiananta, B. and Eliyana, A., 2014. Influence of organizational commitment, transactional leadership, and servant leadership to the work motivation, work satisfaction and work performance of teachers at private senior high schools in Surabaya. Educational Research International, 3(2), pp.82-96.

Wibowo, 2016. Manajemen Kinerja, Edisi Kelima, PT.Rajagrafindo Persada Jakarta-14240. 